\title{
MELANOBLASTOMA OF THE NAIL-BED (MELANOTIC WHITLOW)
}

\author{
ARTHUR E. HERTZLER, M.D \\ HALSTEAD, KAN.
}

DEFINITION

Under this head may be described a malignant disease of the nail-bed marked by the formation of nodules of neoplastic tissue about the border and beneath the nails. The growth is characterized by the formation of melanin and a tendency to spread by way of the lymphatics. Hutchinson called this condition melanotic whitlow, a designation obviously inapt in the more advanced cases. I have adopted the term "melanoblastoma," in harmony with the teachings of Mallory, in order to emphasize the fact that, genetically, they are different both from the sarcomas and carcinomas.

\section{INCIDENCE}

The condition is rare, though obviously not so rare as the literature would indicate. The reported cases do not much exceed twenty. It has been my privilege to treat two of these patents, and, since American literature is all but devoid of case reports, a presentation of my cases, together with a general summary of the recorded cases, will be presented here. The case histories resemble each other so closely that a detailed account of each is uninteresting. Since, however, the literature is not readily accessible, the principal papers heretofore published will be presented in abstract.

\section{REPORT OF AUTHOR'S CASES}

CASE 1.-A widow, aged 64 , a year and a half previously, as a result of a slight injury, had an ulceration beginning along the outer border of the left thumb nail. It was treated with iodin and salves without result. In a year, the greater part of the nail-bed had become involved, and the nail was removed. The pain had never been severe, but it was a constant annoyance. The pain became severe after prolonged use of the thumb.

When she came under my care, the nail was absent and the nail-bed was occupied by a blue-black granular area (Fig. 1, $A$ ). To the touch, the nodules were firm and did not tend to bleed. About the border of the granular area was a border of darkly pigmented tissue. About the relatively unchanged skin small deeply colored areas could be seen through the epidermal covering. There was no involvement of the neighboring lymphatic glands.

The thumb was amputated. It is now two years since the amputation, and the patient still is free from evidence of recurrence.

CASE 2.-A woman, aged 54, four years previously, first noticed a black spot under the left thumb nail near its base. The spot was then about the size of a 
black-headed pin, and looked like a blood blister following a bruise, but there had been no injury and it was not painful. About three months later, the center of the nail became white, dry and scaly and stripped off very easily. In a few months, this central strip of nail had completely separated itself, leaving a strip of healthy nail on either side with a hard, dry surface beneath. There was no soreness, but the area was sensitive to slight injury. The condition remained the same a year and a half. At this time, the remaining portions of the nail became dry and separated. The original black spot did not change until six months ago, when it began to spread and grew up like a wart. It now became sensitive. The patient attributed this to the innumerable slight injuries it received while she was nursing a sick daughter. She tried many kinds of salves and it was burned out a number of times by a physician. Following this the previously healthy skin at the base became brown. Five weeks previously, she had consulted another doctor. He sent her to a dermatologist who applied radium. The condition grew rapidly worse under this treatment and became excessively sensitive.

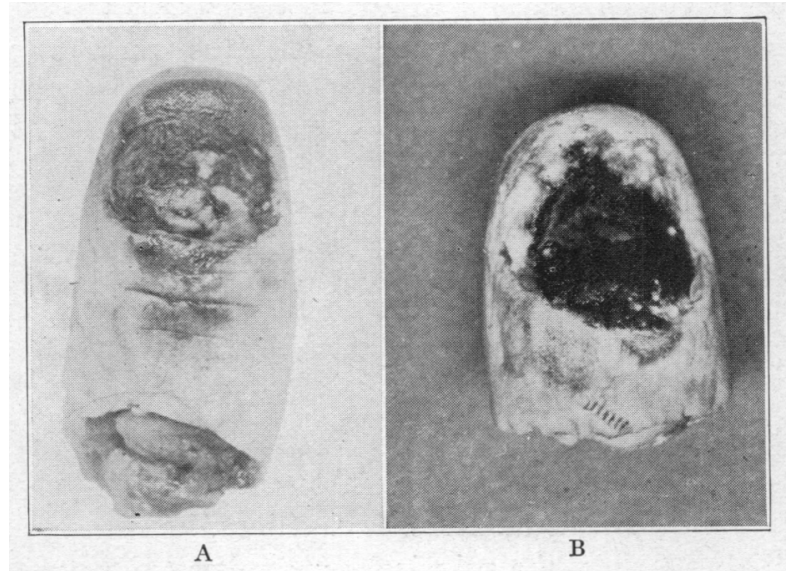

Fig. 1. $-A$, the nail-bed is covered with dry granulations. The surrounding skin is well preserved. At the base of the nail-bed, the tumorous masses are approaching the skin surface from beneath. $B$, the nail-bed is covered with a granular mass in which hemorrhages have taken place. The surrounding skin is in part exfoliated, exposing the developing tumor masses beneath. Above the nail-bed, the tumor masses are still covered with unchanged skin, but they are well distinguished by their color.

When the patient came to see me the nail-bed had a granular surface covered with recently coagulated blood (Fig. 1, B). The granules appeared to have some hemorrhage into their substance. The whole surface was blue-black. The skin surrounding this area was hard, dry and yellowish white. Near the border of the lesion, small brownish black spots shimmered through. The lesion was very sensitive to the slightest touch. The lymph channels and lymph nodes were not involved.

An amputation at the midphalangeal joint was made. Healing took place without reaction.

This patient was operated on only two months ago, hence a recurrence for some time is not to be expected. 


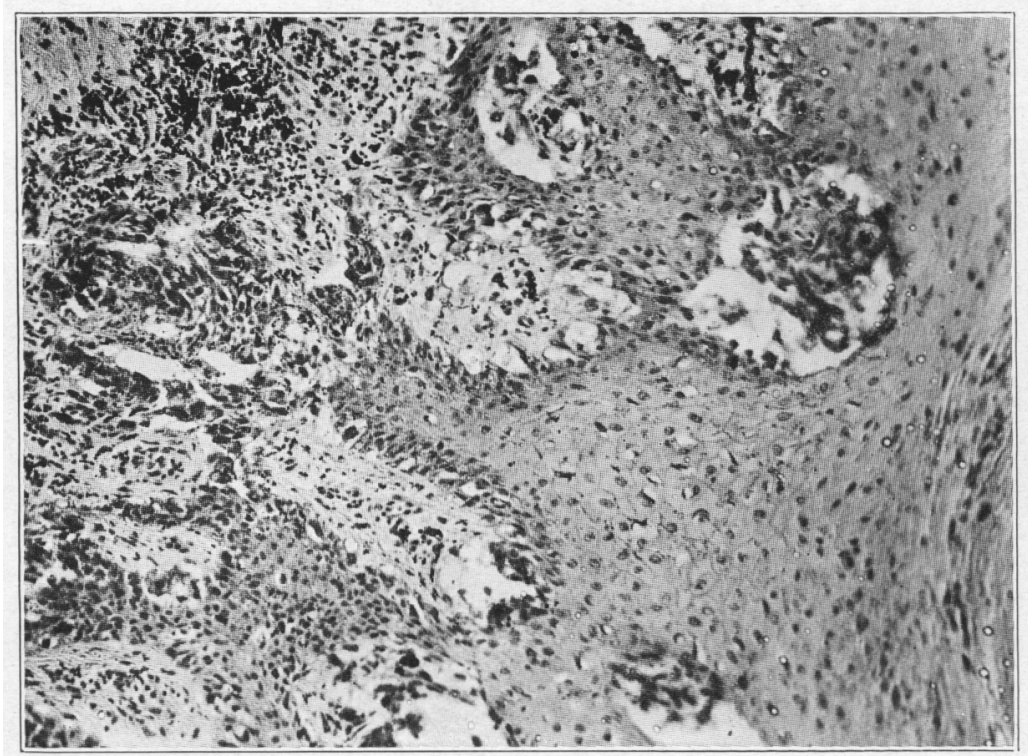

Fig. 2.-Slide from Case 1: The cell masses extend down from the papillary layer of the skin. The farther they advance the more elongated they become. Distributed among and within these cells are abundant pigment granules.

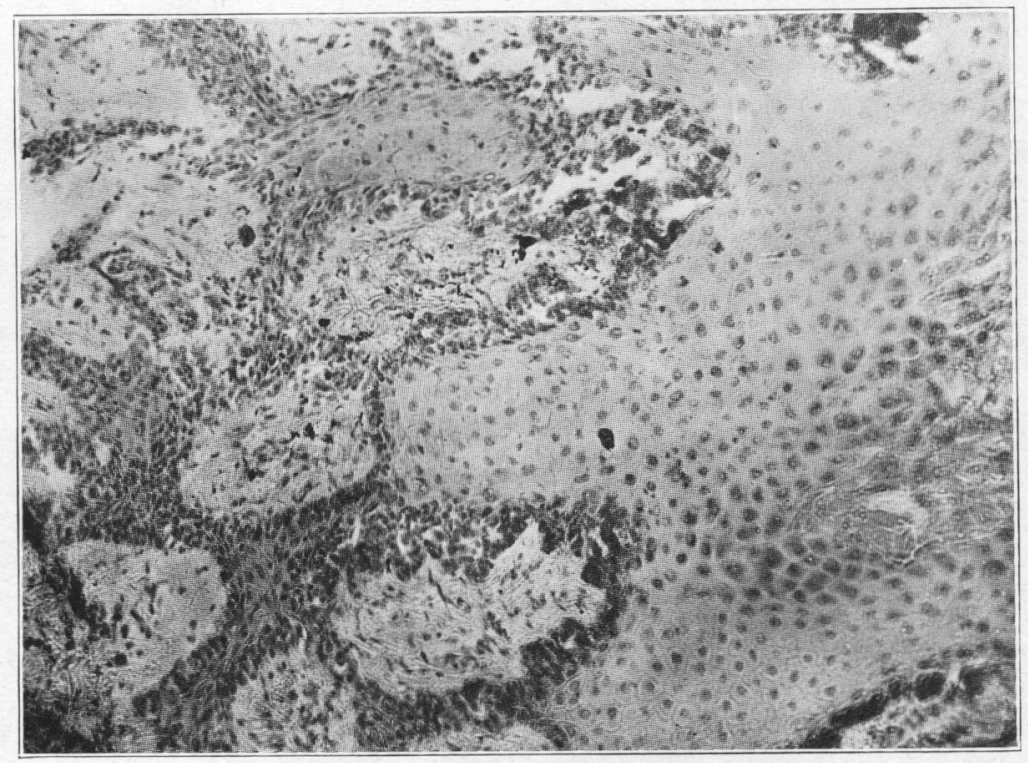

Fig. 3.-Slide from Case 2: The histologic findings are parallel with those in the preceding case. 
Following are the only clearly typical cases that could be found in a somewhat extended search of the literature.

\section{CASES IN THE LITERATURE}

CASE 3 (Boyer ${ }^{1}$ ). A man, aged 57, presented a tumor the size of an egg on the little finger of his left hand. The tumor developed thirty years before as a little black line about the finger nail. This remained stationary for twentyeight years. During the last two years, the line had become inflamed and extended in breadth and was painful. It became nodular as the size increased. The finger was amputated.

CASE 4 (Demargnay and Monod "). - A woman, aged 59, had a tumor occupying the thumb of her left hand by covering the second and part of the first phalanx. It was dark and bled easily. It began as an excresence near the nailbed. It had been removed some months previously and the base cauterized. It reappeared and hard masses appeared in the axilla, and an indurated cord could be felt along the arm. The slide showed large cells containing nuclei and nucleoli.

CASE 5 (Annendale ${ }^{3}$ ).-The patient, aged 56, fifteen months before, had observed a small red ulcer, formed beside the nail of the right index finger. The nail was removed, but the lesion spread. A fungus mass formed, extending to the palmar surface. There was a fine line of demarcation between the denuded and the normal tissue. A strip of skin separated the dorsal from the palmar nodules. After amputation, the dorsal part was found to be pigmented, the palmar pigment free. The slide showed cells of all forms.

CASE 6 (Nieberg ${ }^{4}$ ).-A man, aged 51 , a year and a half before, suffered an injury to the ungual phalanx of his left thumb. A granular area appeared along the nail border, which was frequently cauterized and finally removed. This failing to cure, amputation was performed. Metastases in the axilla followed, these lesions containing pigmented cells. Necropsy showed extensions of the nodules along the vessels to the aorta and vena cava.

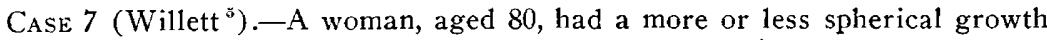
springing from and surrounding the ungual phalanx of the thumb. The surface was nodular and uneven, the skin ulcerated. The nail still embedded in the growth was pushed upward from its bed. The lesion appeared strictly limited to last phalanx, which was involved so that the remains of the bone could not be made out. Amputation was performed. The growth consisted, microscopically, of irregular masses of deeply stained nucleated cells. The cells appeared to be epithelial, similar to those forming a healthy nail. They did not grow from the surface. Their arrangement recalled the structure of rodent ulcer. There were no cell nests. Three years later, there was a mass in the axilla.

CASE 8 (Sacin and Keser ${ }^{6}$ ).-A man, aged 62, developed the lesion six years before entering the hospital, following a small lacerated wound. An ulcer was

1. Boyer: Gaz. méd. de Paris, 1854, p. 212.

2. Demargnay and Monod: Gaz. d. hôp., 1855, p. 415.

3. Annendale: The Malformations, Diseases and Injuries of the Fingers and Toes and Their Surgical Treatment, Edinburgh, 1865, p. 167.

4. Nieberg: Diss. Würzburg, 1882, p. 27.

5. Willett: Tr. Path. Soc., London 46:152, 1895.

6. Sacin and Keser: Jahresb. ü. d. chir. Abt. d. Spit. in Basel, 1885, p. 114. 
formed which secreted abundantly, covering the second and third phalanges of the fourth finger, elongated, with an irregular surface showing pigmented areas. The cervical and axillary glands were enlarged. Amputation was performed. The end-results are not stated.

CASE 9 (Hallé ${ }^{\top}$ ).-A man, aged 46, presented an affection of the thumb which had existed seven years. The nail became deformed, shriveled up and cracked, and finally came off completely. The area of the nail became red and thickened. An incision was made into it, but only blood escaped. The wound did not heal, and the tumor advanced. Curettage and cauterization with a hot iron was performed, followed by a recurrence. A granular surface, dark red, with some dark spots sharply defined from the surrounding pale skin, developed. Amputation of the thumb was performed and two glands were removed between the biceps and the brachial artery.

The tumor was firm and black on section and sharply limited. The skin was destroyed over the surface. The glands removed from the arm were ovoid and definitely encapsulated. The section showed pigment. The slide showed large fusicellular alveolar sarcoma, more or less pigmented.

CASE 10 (Hutchinson ${ }^{8}$ ).-A man, middle-aged, presented a thickened nail along one edge of which was a black line which looked as if it had been touched with lunar caustic. Amputation was performed. Eight or ten years later, the disease recurred, involving the axillary glands.

CASE 11 (Hutchinson ${ }^{\circ}$ ).-A middle-aged man presented a tumor which had been growing on his thumb for several years. The growth was as large as a walnut. It was ulcerated over the whole surface, but showed no tendency to slough or become fetid. Just under the overhanging border of the unswollen skin was a narrow coal black margin.

CASE 12 (Lediard ${ }^{10}$ ).-A woman, aged 40 , had a small melanotic tumor growing from the side of the nail of the index finger. The growth was painless for two years. The nail was torn off, the growth clipped off and the phalanx scraped. The finger was amputated two days later, after examination of the tumor had been made. The growth was three quarters of an inch $(1.8 \mathrm{~cm}$.) long, one-half inch $(1.2 \mathrm{~cm}$.) broad and three quarters of an inch deep. The patient died two years later of numerous melanotic tumors, distributed over the body.

CASE 13 (Faguet ${ }^{11}$ ). A woman, aged 63 , two years before, ran a splinter under the medial border of the left ring finger. The splinter was not removed and a phlegmonous inflammation developed. The splinter was finally expelled, but left a fistulous tract and a tumefied area. Later, a black nodule the size of the head of a pin developed near the fistulous opening. This spread, finally covering the entire nail-bed.

When examined by the author, the entire phalanx had been completely destroyed. The surface of the extremity of the finger was covered with a black, granular, ulcerating surface. The consistency was hard, particularly at the base. Three or four glands the size of a little nut were discovered in the axilla.

7. Hallé: Bull. de la Soc. Anat. de Paris 58:436, 1883.

8. Hutchinson: Am. J. M. Sc. 91:470, 1886.

9. Hutchinson: Tr. Path. Soc., London 36:468, 1885.

10. Lediard: Tr. Path. Soc., London 39:307, 1888.

11. Faguet: Arch. clin. de Bordeaux, 1894, No. 18, p. 448. 
At operation, seven glands, black on section, were found in the axilla. Metacarpophalangal amputation of the finger was performed. The section of the tumor was mottled black and brown, with lighter areas. The slide showed small round cells, separated from one another by small bundles of connective tissue. Other areas show definite epithelial structure, without intercellular connective tissue, but with elongated cells.

CASE 14 (Coley, W. B..$^{12}$ ).-A man, aged 37, seven years before observation, had bruised his thumb. Several years later, he bruised it again. It soon became painful, and five months later discoloration about the nail appeared. It was examined by L. L. McArthur, who called the lesion melanotic sarcoma of the round cell type. Amputation was performed, and a few months later shot-like nodules appeared in the skin of the wrist. Soon similar tumors occurred in various parts of the body. The patient was treated with toxins, and improvement followed, but soon large tumors appeared, and the patient died.

CASE 15 (Trimble, Wm. B. ${ }^{13}$ ).--A woman, aged 39, two months before had run a splinter under the thumb nail. Suppuration followed, and a growth the size of a walnut developed. The palmar surface of the skin remained unaffected. The tumor was a fungus mass which overlapped the healthy skin. Amputation was performed.

CASE 16 (Trimble, Wm. B. ${ }^{13}$ ).-A man, aged 45, whose nail, six months before observation, split slightly, and later came off entirely, noticed small pigmented spots in the nail bed. When first examined, the thumb showed a large fungus mass 2 by 3 inches $(5$ by $7.5 \mathrm{~cm}$.) involving the whole distal phalanx. Amputation was performed.

Specific treatment was given in each case for a month, without result.

CASE 17 (Murphy, J. B. ${ }^{14}$ ). - A man, aged 56, six years before, noticed a slight serous discharge with reddening and irritation under the tip of the nail of the right middle finger. The finger was amputated three years later.

Five weeks later, enlarged epitrochlear and axillary nodes were removed. Two years after this, a node the size of a coconut appeared in the axilla. This was removed.

Murphy assumed that the tumor arose from the irritation of a "wart."

\section{PATIIOLOGY}

Both of my cases represented a relatively early stage of the disease. They both presented the characteristic black border about the lesion. The lesion was granulomatous and looked out through a relatively unchanged skin. In some situations, small black points could be seen shimmering through the skin. This is well shown just about the nail-bed in Figure 1. The important point in the gross appearance is the fact that the growth seems independent of the skin, growing from beneath and displacing it.

The slides from my cases resemble each other so closely that the same description applies to both. Just beneath the epithelial layer, the

12. Reported in discussing a paper by Galloway on pathologic pigmentation preceding malignancies.

13. Trimble: Am. Med. 5:788, 1903.

14. Murphy: Murphy's Clinics 14:663, 1915. 
tumor cells extend in more or less fringelike arrangement (Figs. 2 and 3). These projections seem to be direct continuations of the epithelial layer. The projections extend downward with little tendency to nest formation. The cells tend to become elongated and the nuclei pronouncedly ovoid. The continuation from the epithelial cells is only apparent. Because of the subsequent development and the clinical course, we are warranted in assuming that it is the chromatophore cells that form the starting point of these tumors.

\section{PATHOGENESIS}

The genesis of pigmented tumors has been much discussed. Ribbert is of the opinion that they are derived from the chromatophores. These cells lie beneath the epidermis, particularly along the blood vessels. Gibson and $\mathrm{I}^{15}$ made a study of the pigmented tumors of the lower extremity. We showed that the clinical course of all pigmented tumors was strikingly similar, though the histologic structure may vary markedly. In Figure 16 of our paper, the histologic picture resembles the slides from the cases herein reported. Other slides, as Figures 15 and 17, show, respectively, an alveolar and a spindle form arrangement. We pointed out that, notwithstanding the variation in the histologic appearance of the physical characters of the tumor on the slides, the clinical course is the same. The tendency is to local recurrence, particularly spreading to the neighboring lymph glands or along the lymphatics.

Exactly the same thing is observed in the tumors of the nail-bed of the fingers. Local recurrence and lymph gland metastases are reported in all cases in which the course has been followed long enough. The histologic diagnosis of the reported cases has shown a great variation, carcinoma, sarcoma and sarcocarcinoma. In all these pictures, the clinical course is the same. It seems fair to assume that when the course is so markedly similar, the underlying conditions must be the same.

The clinical course and the histologic picture resemble the like lesion of the lower extremity. I believe the term "melanotic whitlow" should give place to the more accurate term "melanoblastomas of the nail-bed."

\section{DIAGNOSIS}

The appearance of a slowly developing granular area about the nail-bed, showing a pigmented border is characteristic of the disease. When the nail has been lost at the time that the examination is made, the history of onset and the deep pigmented areas beneath the otherwise unchanged skin leave no doubt as to the nature of the disease.

15. Hertzler and Gibson: Ann. Surg., July, 1914, p. 89. 
PROGNOSIS AND TREATMENT

Apparently, all patients so afflicted sooner or later die of the disease. Some have remained free as long as ten years.

From what we know of like lesions in the lower extremities, there is reason to hope that early diagnosis and prompt amputation may produce a cure. Roentgen ray and radium, in these as in all melanotic disease, are worse than useless. ${ }^{16}$

16. In addition to the references already given, the following will be found of interest:

Galloway: Brit. M. J. 2:873, 1897.

Wheeler: Proc. Path. Soc., Dublin, 1880-1881, N. S. 9, p. 171. 